\title{
Problems of Proper Planning In Effective Teaching of High School Students in Salt Schools
}

\author{
Mohammad Nemer Abdallah Alkhararbeh ${ }^{1}$ \\ ${ }^{1}$ Researcher, Directorate of Education, Salt City, Jordan \\ Correspondence: Mohammad Alkhararbeh, Researcher, Directorate of Education, Salt City, Jordan, P.O. Box \\ 182637 Amman, 11118, Jordan. E-mail: mostafahelal27@yahoo.com
}

Received: March 21, 2019

doi:10.5539/ijbm.v14n6p53
Accepted: April 23, 2019

Online Published: May 16, 2019

\begin{abstract}
The study aims to investigate the levels of teaching planning problems in the secondary schools, in Salt City in Jordan, in its three stages; planning problems of lesson's preparation, planning problems of teaching implementation, and planning problems of teaching evaluation. To achieve this aim, descriptive analytical approach was used with a questionnaire which was used as the study instrument. The study sample was calculated to be (152) teachers who were selected randomly. The study results found that teaching planning levels in salt secondary schools were found in the medium level. Moreover, it was found that there is not significant difference between means of the sample's responses about the problems of teaching planning due to the gender variable of the secondary schools 'teachers. Finally, based on the study results, a set of recommendations were provided.
\end{abstract}

Keywords: planning problems, teaching implementation, students, secondary schools

\section{The General Framework}

\subsection{Introduction}

Jordan's poverty to economic and natural resources reinforced the country to invest in the education sector. Therefore, Jordan's governments through the past decades devoted huge efforts to invest financially and humanly in this sector. Hence, these investments in the education in a country suffering from limited economy made the use of human resources highly necessary. Today, the Hashemite Kingdom of Jordan occupies an advanced position on Arab educational indicators that include the quality and efficiency of the educational process.

It is noteworthy that the interest in planning and teaching methods is increasing day by day, and there is not generalization of a teaching method, rather there are many educational schools dealing with a wide variety of these methods that can be classified based on their effectiveness, their effect, and advantages and disadvantages (Alsharari, 2017). On the other hand, the problems of planning in teaching are increasing because of the people frequent needs to learn, learning and explosion of knowledge, progress in scientific fields, and continuous development of information technology (Al Absi, 2004).

Generally, teaching in schools has received great attention in Jordan, especially in the secondary stage that has been given special attention because it is the pre-university stage and derives its philosophy and objectives from the two stages: primary and intermediate stages (Ahmad, 2011). Moreover, the secondary stage is linked to a series of students' growth stages: physical growth, mental growth, and emotional growth. All these factors and others make the school's administration has more burden in the preparation of secondary school students in terms of social, economic, political and scientific concepts that should be supportive to the next educational stages in universities (Al-Zboon \& Hasan, 2014).

Although Jordan's education witnessed an obvious development at all levels, it still suffers from some problems that need to be continually overseen and controlled (Khasawneh, 2011). As a complicated and interferential process, to enhance and develop education, every component of the process needs to be improved and carefully integrated with the other components in the educational series. Teaching is considered as one of the main components of the educational process, and all segments must be built and developed in an integrated manner (Al-Mohsen \& Al-Kilani, 2009). Teaching planning in schools is the basic segment of the process, and if it is not given sufficient interest, the educational process as a whole will not be successful. 
For a few previous years, several studies (e.g: Al-Mohsen \& Kilani, 2009; Al-Zboon \& Hasan, 2014; Khasawneh, 2011) have been urging the problems of teaching dilemma in school's stages, but few of them have been focused on the teaching planning process. The current study has discussed the problems of teaching planning, as the basic element of the teaching process, giving a robust threshold for new studies concerning with this field to search obstacles facing teaching process in all its phases (planning, implementation, and evaluation)

\subsection{Research problem}

Many studies indicate that there are obvious problems in teaching planning in Jordan (Khasawneh, 2011; Stave, Tiltnes, Khalil, \& Husseini, 2017). After studying the reality of the field, the researcher indicates that the secondary school teachers have a clear weakness in the planning of effective teaching. In most countries throughout the world, teachers of the secondary stage are given more importance because of their great influence on the students' attitudes towards university education (Kellen, 1996). As a result of change in the curricula, the emergence of new developments in the teaching methods, and the technological progress associated with the educational process, there has been an urgent need to review the planning of advanced teaching methods. Thus, the problem of the study can be manifested in the following questions:

\section{Q1: What Is the Level of Proper Planning Problems for Effective Teaching Among Secondary School Teachers in Secondary Schools of Salt City?}

From the first main question, the following questions arise:

Q1-1: What is the level of proper planning problems of lesson's preparation among secondary school teachers in secondary schools of Salt?

Q1-2: What is the level of planning problems of teaching implementation among secondary school teachers in Salt city?

Q1-3: What is the level of planning problems of teaching evaluation among secondary school teachers in Salt city?

Q2: Are There Statistically Significant Differences Between The Average Responses of Secondary School Teachers In Salt City About The Proper Planning of Effective Teaching Due To The Gender Variable?

\subsection{Importance of the Study}

The current study has a both theoretical importance and practical importance, as follows:

\section{A. Theoretical importance:}

The current study will provide ample theoretical literature in the following areas:

A-1: The current study - to the knowledge of the researcher - is considered as a new research focusing on improving the teaching process in the secondary schools in Jordan by investigating the problems of teaching planning in all its phases.

A-2: The results of the current study are considered as supportive factor for the researchers interested in the educational field to investigate the problems facing the other phases, rather teaching planning, to improve the educational path in Jordanian schools.

\section{B. Practical importance:}

B1. In practice, the current study will help teachers find appropriate solutions to planning problems in the teaching field. And thus help teachers identify strengths and weaknesses of their educational performance.

B1. Accordingly, based on the previous importance (B1) the school administration can take the proper proceedings that can ensures the continual improvement and development of the school education.

\subsection{Research Aim and Objectives}

The current study aims to identify the planning problems of effective teaching among secondary schools' teachers in Salt city. From this main aim, the following objectives can be formulated:

1) To investigate the planning problems of lesson preparation among secondary schools' teachers.

2) To investigate the planning problems of teaching implementation among secondary schools' teachers.

3) To investigate the planning problems of teaching evaluation among secondary schools' teachers.

4) To explore whether the gender variable of the study sample plays a significant role in their evaluation of the planning problems of effective teaching in secondary schools. 


\section{Theoretical Background \& Previous Studies}

\subsection{Theoretical Background}

\subsubsection{Effective Teaching}

Teaching is a set of procedures and practices that help teachers to achieve the educational goals. The teaching process includes main skills (planning, implementation and evaluation) that underpin the teacher's readiness to deal with the emergent factors and their created problems within the classroom, and provide appropriate solutions and behaviors to control these factors and solve the problems (Puamau, 2006). Teaching is expressed as the way to overcome the difficulties of implementation of the curriculum by drawing the perceptions and preparing the necessary procedures to achieve its objectives with the least potential and the greatest benefit. Planning is used in teaching to achieve the goals in the best face and at least time and effort on all parts of the educational process (Lofstorm, 2007).

Students' teaching at the secondary level depends basically on the method that drives the internal motivation at the students and generates their interest to reach the desired goals. With the explosion of science, knowledge, and progress in the areas of information technology, the methods of teaching has become necessary to be more integrative, therefore it is wrong to consider that teaching planning is exclusively concerned just with a specific stage, rather it is important in all stages of education to change and develop educational institutions and traditional teaching methods (Salfi \& Saeed, 2007).

The proper teaching planning is a vital element in the successful teaching process. According to Saeed, Gondal, and Bushra (2005), Effective teaching may be hard work, because it is a complicated activity that requires both teachers and students to make a series of decisions, based on the curriculum objectives, and harmonization between all its complementary parts. However good planning is a means to support this type of teaching, where it can help the teacher to prepare for the next lesson, next semester, and next year.

\subsubsection{Importance of Proper Planning for Effective Teaching}

Kombra (2006) defined Teaching Planning as a hard intellectual work that needs a great and cooperative effort from teachers and schools' administration to develop a set of steps to realize a high degree of efficiency and effectiveness in the teaching process within the materials and human resources available in the school. Teaching Planning is divided into two types; which are long-term planning that aims to support the teaching process during the academic year, or semester, and a short term that aims to support the teaching process for, day, or week (Khan \& Shah, 2002).

Teaching Planning is a set of ideas, actions and measures that the teacher takes in advance before implementing the lesson in order to ensure better education (Puamau, 2006). The planning for teaching depends on a set of strategies, objectives and teaching methods that must be appropriate to the level of the students and the topic of the required lesson (Lofstorm, 2007). Teaching planning requires the selection of learning and teaching activities, in addition to the ability of the teacher to think and balance the possibilities available to students and their previous experiences. Through teaching planning, the teacher can increase the professional and educational growth of the learners motivating them to face difficulties of learning with confidence and morale, avoid embarrassing situations through their education, and have good ability to identify their learning strengths and weaknesses (Drouze, 2011).

\section{1) Planning problems of lessons' preparation (PPLP)}

Lessons' preparation needs to be planned in such a way that can support the lateral phases of students' education (i.e.: teaching implementation planning and teaching evaluation planning). This phase of planning is not only related to the planning phases, but also it is very crucial for every stage in its application; teaching implementation, and teaching evaluation (Collins, 2016). Therefore, lesson's preparation planning is considered as the basic of teaching planning in general as well as teaching application phases. Planning of lesson's preparation includes a set of components that should be taken by the teachers to provide effective education for their students. These components are very compatible and integrative (Fua, 2001; Khasawneh, 2011; King, 2004; Puamau, 2006):

a) Lesson educational objectives:

To help students understand the lesson well and teachers provide eligible teaching, a set of objectives must be addressed so that all lesson's parts be consistent in a way that is easy for the student to determine the main ideas of the lesson and connect them smoothly. 
b) Lesson Procedural Objectives:

For each lesson, there should be exist some of objectives that help students to be more interactive, with their class room friends as well as their teachers, and hence be able to create and share new knowledge. Such these objectives need to be applied using some educational strategies.

c) Teaching Means:

Each lesson may need particular means to be taught effectively, especially with the increasing developed techniques that help the students to expand their thinking to be more creative. For instance, a teacher may need to use data show equipment to display some videos and new information to support his/her students' understanding.

d) Information Resources:

With ongoing development of education policies and strategies, teachers may need to necessarily search for new resources to get new information that can support the lesson's title and its main ideas. For instance, the teacher of mathematics material may need to use electronic search engine to attain more methods of solutions for some complex mathematical problems, and make them easier to be solved by his students.

For all these and other elements of proper teaching planning, teachers may face many problems that must be tackled in modern and effective methods.

\section{2) Planning problems of teaching implementation (PPTI)}

Consistent with the planning of lessons' preparation and as a necessarily pre- implementing element, Planning of teaching implementation is very crucial for education's success (Haddad, 1995; King, 2004). In this phase, teachers must pursue a proper and effective method of planning that can lead to effective education. In this process, the teacher should know how to put each component of the previous phase (i.e.: planning of lesson's preparation) in its suitable position to give more effective educational synergy (Fua, 2001). However, in this critical phase of teaching planning, the teacher may face some obstacles that need to be solved by assistance from his school's administration and within the framework of its educational capabilities.

\section{3) Planning Problems of Teaching Evaluation (PPTE)}

This type of teaching planning is highly dependent on the two former stages, planning of lesson's preparation and planning of teaching implementation, and soundly integrative technique with them. This final phase of planning must be designed and developed by the school's administration (Fua, 2001; Stave, Tiltnes, Khalil, \& Husseini, 2017). By planning of the teaching evaluation, the school's administration can address challenges of teaching for every teacher in the school by determining his strength and weakness positions. Based on the planning of teaching evaluation, the school' principal supported by his subordinates can take the essential procedures to improve and develop the educational process (Afsahi, 2016). Particularly, in the secondary school' stage, as a result of the planning of teaching evaluation, the school's administration may have to undergo some teachers to specific training and development programs, and in other cases it may replace one by another according to some needed educational competences.

\subsection{Previous Studies}

Al-Zboon and Hasan (2014) conducted a study that aimed to measure the degree of applying the strategic planning stages on the governmental secondary schools of Directorates of Education in Amman from the perspective of schools' principals and supervisors. The study population was composed of all educational principals and supervisors working in these Directorates with a number of (150). The study used the Comprehensive survey method in which all the study population members were included in the study sample. The analysis results found that the total degree of applying the strategic school planning with all its stages at the governmental secondary schools were medium.

Al-Qarni's study (2012) aimed at identifying strategic planning in public education schools in Taif Governorate in Saudi Arabia. In order to achieve the aim of the study, the researcher used the analytical descriptive method with a questionnaire that was used to collect data about the problem of study. The study population consisted of all principals of the public schools for boys in Taif governorate for the academic year (2010/2011). The study concluded with a set of results. The most important one of these results was that the requirements' level for schools' education planning in Taif governorate was very high.

Drouze (2011) conducted a study aimed at detecting the degree of Palestinian teachers' observance of Bloom's levels of knowledge objectives when planning the curriculum. To achieve this goal, the study selected a simple random sample of (400) teachers in Qalqilya schools in the West Bank. The study used a questionnaire 
containing 98 items. The data were analyzed using descriptive statistics and statistical analysis by (SPSS). The analysis results showed that teachers apply Bloom's levels of knowledge objectives at a high level. The study also found that secondary school teachers apply Bloom's levels of knowledge objectives better than primary stage teachers.

\section{Research Methodology}

The current study is one of the field studies in which the researcher used the analytical descriptive approach as the most suitable method for the current study, in which the researcher sought to identify the planning problems in effective teaching of secondary school students.

\subsection{The Study Targeted Population \& Sample Size}

\subsubsection{The Study Population}

The study targeted population is composed of all teachers, males and females, teaching students of the secondary school stage in Salt city in Balqa province of the first semester of the academic year 2018/2019 with a number of (252).

\subsubsection{The sample Size}

To obtain the appropriate sample size from the study community, Thompson equation (Thompson, 2002: 10) was applied: $n=\frac{N \times p(1-p)}{\left[\left[N-1 \times\left(d^{2} \div z^{2}\right)\right]+p(1-p)\right]}$

Where:

$\mathrm{N}$ : The size of the study community,

z: the standard score corresponding to the confidence level of $(0.950)$ which is equal to 1.96 ,

$\mathrm{d}$ : The ratio of error and equivalence (0.05), and

$\mathrm{p}$ : is: the ratio of availability of the property and neutral which is equal to (0.5).

According the equation above, the sample size has been calculated:

$$
\mathrm{n}=\quad \frac{252 \times 0.5(1-0.5)}{\left[\left[252-1 \times\left(0.05^{2} \div 1.96^{2}\right)\right]+0.5(1-0.5)\right]}
$$

$\mathrm{n}=152$

\subsection{Description of the Study Sample}

Table (1) shows the distribution of the study sample in secondary schools of Salt according to the variables of the study: (type, qualification, and years of experience).

Table 1. Distribution of the study sample by (gender, qualification level, \& experience)

\begin{tabular}{llll}
\hline Variables & Variable Categories & frequency & Percent (\%) \\
\hline \multirow{3}{*}{ Gender } & Male & 71 & 46.8 \\
& Female & 81 & 53.2 \\
& Total & $\mathbf{1 5 2}$ & $\mathbf{1 0 0}$ \\
& Diploma & 12 & 8.0 \\
Scientific qualification level & Bachelor & 83 & 55.0 \\
& Postgraduate & 57 & 37.0 \\
& Total & $\mathbf{1 5 2}$ & $\mathbf{1 0 0}$ \\
& $<5$ & 61 & 40.0 \\
experience & 5 To 10 & 64 & 42.0 \\
& $>10$ & 27 & 18.0 \\
& Total & $\mathbf{1 5 2}$ & $\mathbf{1 0 0}$ \\
\hline
\end{tabular}


The distribution of the sample in Table (1) shows that the largest number of the sample was for female (81), while the number of males (71). In terms of scientific qualifications, the highest number was for bachelor's degrees with (83). For the experience variable, the largest number was for those with intermediate experience (from 5 to 10 years) with a number of (64), followed by the category of short experience (less than 5 years) with a number of (61), while there were (27) of respondents with long experience (more than 10 years).

\subsection{Description of the Study Instrument}

The literature relating to the field of the current study was reviewed, and accordingly a questionnaire was designed to achieve the study objectives. The questionnaire is composed of two main parts: The first part, which includes the preliminary data for the study sample in terms of gender, qualification and years of experience, whereas the second part includes (27) items which aim to measure the problems of proper planning in effective teaching at the secondary level and distributed over three main dimensions. The first dimension measures Planning Problems of lesson's preparation with (10) items, the second dimension measures planning problems of teaching implementation with (8) items, and the third dimension measures planning problems of teaching evaluation with (9) items.

\subsection{Testing Validity \& Reliability}

To test the validity and reliability of the Study, a pilot test was implemented on (40) teachers (17 males and 23 females), who were selected randomly and not included in the original study sample.

\subsubsection{Testing Validity}

a) Content validity: To confirm the instrument validity, it was presented to (11) arbitrators from four Jordanian universities, who are highly specialized in the study field and having good knowledge to justify its items. Then, according to the arbitrators' amendments and suggestions, the instrument with (30) items were adapted; five items were removed, seven items were modified, and two items were added. The final version of the questionnaire was reformed with (27) items distributed on three main dimensions.

\section{b) Constructive Validity}

\section{b. 1 Internal Consistency:}

Pearson Correlation coefficients were used to determine the Internal consistency between each set of items with their expected dimension.

Table 2. Correlation coefficient values to measure internal consistency

\begin{tabular}{llllll}
\hline \multicolumn{5}{l}{ Planning Problems of lesson's preparation Planning problem of teaching implementation Planning problems of teaching evaluation } \\
\hline No. of item & Pearson correlation & No. of item & Pearson correlation & No. of item & Pearson correlation \\
\hline 1 & $0.934^{* *}$ & 1 & $0.787^{* *}$ & 1 & $0.780^{* *}$ \\
2 & $0.821^{* *}$ & 2 & $0.791^{* *}$ & 2 & $0.791^{* *}$ \\
3 & $0.909^{* *}$ & 3 & $0.874^{* *}$ & 3 & $0.901^{* *}$ \\
4 & $0.854^{* *}$ & 4 & $0.880^{* *}$ & 4 & $0.851^{* *}$ \\
5 & $0.847^{* *}$ & 5 & $0.902^{* *}$ & 5 & $0.900^{* *}$ \\
6 & $0.748^{* *}$ & 6 & $0.868^{* *}$ & 6 & $0.852^{* *}$ \\
7 & $0.896^{* *}$ & 7 & $0.884^{* *}$ & 7 & $0.821^{* *}$ \\
8 & $0.889^{* *}$ & 8 & $0.908^{* *}$ & 8 & $0.846^{* *}$ \\
9 & $0.854^{* *}$ & & & 9 & $0.813^{* *}$ \\
10 & $0.789^{* *}$ & & & & \\
\hline
\end{tabular}

Note. The correlation coefficient is statistically significant at the significance level $(\alpha=0.01)^{* *}$

Table 2 shows that the correlation coefficients of each set of items with their expected dimension are statistically significant at the level of $\alpha=0.01$, which refers to the consistency of each set of items with their expected dimension.

\section{b. 2 Composite Consistency:}

To verify the composite consistency of the study, Pearson correlation coefficients were calculated between the three dimensions in the instrument as well as between each dimension with the total instrument. 
Table 3. The correlation coefficients between the study dimensions, and between each dimension with the total degree of the instrument

\begin{tabular}{|c|c|c|c|c|}
\hline Dimension & PPLP & PPTI & PPTE & $\begin{array}{c}\text { Instrument } \\
\text { (Total) }\end{array}$ \\
\hline Planning Problems of Lesson's Preparation & & $0.916^{* *}$ & $0.757 * *$ & $0.926 * *$ \\
\hline Planning Problems of Teaching Implementation & & & $0.867 * *$ & $0.957 *$ \\
\hline Planning Problems of Teaching Evaluation & & & & $0.927^{* *}$ \\
\hline
\end{tabular}

Note. The correlation coefficient is statistically significant at the significance level $(\alpha=0.01)^{* *}$

It can be noted from Table (3) that the values of correlation coefficients between the study tool dimensions ranged between (0.757) and (0.916) and statistically significant at $(\alpha=0.01)$, which refers to the existence of consistency among the dimensions of the study instrument in measuring the problems of proper planning in Effective teaching by teachers of secondary schools. Moreover, the correlation coefficients between each dimension of the three dimensions with the total degree of the instrument ranged between (0.926) and (0.957). These values are statistically significant at the level of significance $(\alpha=0.01)$, indicating that the three dimensions of the study instrument suitable for measuring the problems of "proper planning in the effective teaching" of secondary schools.

\subsubsection{Testing Reliability}

After verifying the validity of the study instrument, the reliability coefficients of the study instrument and its three dimensions were extracted using the Cronbach's alpha equation (Table 4).

Table 4. Cronbach's Alpha Coefficients of the study dimensions

\begin{tabular}{lll}
\hline Dimensions & No. of Items & Cronbach's alpha coefficients \\
\hline Planning problems of lesson's preparation & 10 & 0.958 \\
Planning problems of teaching implementation & 8 & 0.951 \\
Planning problems of teaching evaluation & 9 & 0.947 \\
Instrument (Total) & $\mathbf{2 7}$ & $\mathbf{0 . 9 6 8}$ \\
\hline
\end{tabular}

The results in Table 4 shows that the reliability coefficient of the study instrument is (0.968), Also, The values of reliability coefficients for the dimensions ranged between (0.947) and (0.958). Therefore they are suitable for the current study, because they are more than the cut-off value $(0.60)$.

\subsubsection{Testing Multi-Collinearity and Normality}

The sample size is large (152). Thus the central limit can be applied. Thus there is not normality problem. For testing multicollinearity, Tolerance, and Variance Inflation Factor (VIF) were used, in which when the tolerance value were found not $(<0.1)$ and VIF were found $(\leq 10)$, it should be not multicollinearity.

Table 5. Variance Inflation Factors (VIF) and Tolerance of the variables.

\begin{tabular}{lll}
\hline Dimension & Tolerance & VIF \\
\hline Planning Problems of teaching implementation & 0.715 & 1.52 \\
Planning Problems of teaching Preparation & 0.624 & 1.62 \\
Planning Problems of teaching Evaluation & 0.581 & 1.42 \\
\hline
\end{tabular}

Table 5 confirms that tolerance values are $(>0.1)$, and those of VIF are found $(<10)$, which means that there is not multicollinearity problem.

\section{The Study Results}

4.1 Results relating to the first main study question: What Is the Level of Proper Planning Problems for Effective Teaching among Secondary School Teachers in Secondary Schools of Salt City?

The measurements of Mean, standard deviation were used to limit the level of each one of the study dimensions (Table $6)$. 
Table 6 . The degree of proper planning problems of effective teaching at the study sample

\begin{tabular}{llllll}
\hline Dimension order & Dimension num. in instrument & Dimension & Mean & S.D & Level \\
\hline 1 & 2 & Planning Problems of teaching implementation & 3.45 & 0.64 & medium \\
2 & 1 & Planning Problems of lesson's Preparation & 3.42 & 0.67 & medium \\
3 & 3 & Planning Problems of teaching Evaluation & 2.78 & 0.93 & medium \\
Instrument (Total) & & & 3.21 & 0.811 & medium \\
\hline
\end{tabular}

Table 6 indicates that the level of the problems of proper planning in the effective teaching at secondary school teachers in Salt city in general (the tool as a whole) was in a medium score with an arithmetic mean of 3.21 and a standard deviation of 0.81 .

Regarding the level of each dimension reality of the study, the second dimension, "Planning Problems of teaching implementation", came in the first order with an arithmetic mean of 3.45, standard deviation of 0.64 , and medium score. This may be due to the lack of experience of many teachers, where sufficient experience helps the teacher build successful plans that need sufficient knowledge to address the problems of teaching, strengths and weaknesses in the curriculum. Accordingly, experienced teachers can know how to solve these problems. Also, other reasons for the classification of the reality of planning problems of teaching implementation to be in the medium score are that; the teachers usually tend to depend on the traditional methods in their teaching, the lack of infrastructure eligible for schools, the collapse of classrooms and crowded schedule. Such these factors do not give the opportunity for the teacher to build efficient plans.

The dimension "Planning Problems of Lesson's Preparation" has located in the second order, with an arithmetic mean of 3.42 , standard deviation of 0.67 , and medium score. This high result is due to the fact that the systematic plans of the school curricula need to be modified to achieve the objectives that were set for them, and the need to focus on the creative and innovative side of the students.

While the third dimension "Planning Problems of teaching Evaluation " came in the third order with an arithmetic mean 2.78 , standard deviation of 0.93 , and medium score. This result is due to the fact that the teachers may do not pay much attention to planning the teaching evaluation. This appears obviously by the lack of a specific mechanism that makes it easier for teachers to evaluate, not to activate the role of feedback from students, and to rely on a specific traditional pattern in the evaluation.

4.1.1 Results Relating to The Second Main Study question: "Are There Statistically Significant Differences Between The Average Responses of Secondary School Teachers In Salt City About The Proper Planning of Effective Teaching Due To The Gender Variable? " due to the gender?

Table 7. Independent samples T- test results

\begin{tabular}{|c|c|c|c|c|c|c|c|c|}
\hline Dimension & Gender & Num. & Mean & SD & $\mathbf{T}$ (calculated) & Freedom Degrees & Sig. & Result \\
\hline \multirow{2}{*}{ Problems' planning of lesson's preparation } & Male & 117 & 3.26 & 0.64 & \multirow{2}{*}{2.446} & \multirow{2}{*}{150} & \multirow{2}{*}{$0.015 *$} & \multirow{2}{*}{ Sig. } \\
\hline & Female & 133 & 3.58 & 0.6 & & & & \\
\hline \multirow{2}{*}{ Problems' planning of teaching implementatio } & Male & 117 & 3.36 & 0.69 & \multirow{2}{*}{2.086} & \multirow{2}{*}{150} & \multirow{2}{*}{$0.038^{*}$} & \multirow{2}{*}{ Sig. } \\
\hline & Female & 133 & 3.54 & 0.72 & & & & \\
\hline \multirow{2}{*}{ Problems' planning of teaching evaluation } & Male & 117 & 2.79 & 0.65 & \multirow{2}{*}{1.011} & \multirow{2}{*}{150} & \multirow{2}{*}{0.313} & \multirow{2}{*}{ Not sig. } \\
\hline & Female & 133 & 2.77 & 0.63 & & & & \\
\hline \multirow{2}{*}{ Instrument (Total) } & Male & 117 & 3.14 & 0.55 & \multirow{2}{*}{1.071} & \multirow{2}{*}{150} & \multirow{2}{*}{0.285} & \multirow{2}{*}{ Not sig } \\
\hline & Female & 133 & 3.3 & 0.53 & & & & \\
\hline
\end{tabular}

Note. * significant at $(\alpha=0.05)$

"T" analysis of independent samples (Table 7) was done to detect the significance of the differences in the responses of the sample members due to the gender variable (male, female). The results showed the following:

The calculated " $T$ " value of the differences between the male and female responses to all study dimensions as well as the dimension of "Planning Problems of Teaching Evaluation" were (1.071) and (1.011) respectively, and these values are not statistically significant at the significance level $(\alpha=0.05)$. This result means that teachers in the secondary schools of Salt City assessed the reality of "proper planning of effective teaching" in general, and 
"problems planning of teaching evaluation" in similar manner regardless of their gender.

This result can be interpreted by the fact that all secondary school teachers, males and females, practice their education in one educational institution possessing the same policy and administration, the why that makes all teachers subject to the same regulations, laws, and decisions, which ultimately reflect on their similar evaluation of "problems of Proper planning in effective education "in general and "planning problems of teaching evaluation".

On the hand, it can be noted that there is significant difference in the sample responses about the two dimensions" Problems' planning of lesson's preparation" and "Problems' planning of teaching implementation" The result may be that female teachers are more keen to plan for the lesson before and after its preparation, which makes them more likely to be more aware of planning problems in those two cases than male teachers.

\section{Conclusion}

Students' education in Jordan has stridden a long pace and witnessed an obvious development at all levels; school level, undergraduate level, and postgraduate level. Despite this relatively wonderful leap, education has some obstacles that limit its ambition to be at the advanced thresholds of excellence throughout the world. Students' education in schools, especially in the secondary stage, is considered as the backbone of the education in general and the fundamental base for all lateral educational levels. However, some scholars having interest in this field have found some dilemma that caused the schools' education lag behind, which are embedded in one or more of the education phases; planning, implementation, or evaluation. The study results found that the planning problems of lesson's preparation, teaching implementation, and teaching evaluation at the teachers of the secondary stage in Salt city are at the medium level, and based on this result a set of recommendations have been provided.

\section{Limitations \& Future Research}

The current study has been limited by specific limitations: first, it has been focused to investigate the problems of planning process in all its stages, lesson's preparation planning, implementation planning, and evaluation planning. Second, the study has been focused on the secondary stage as the stage closest to the higher educational stages. Finally the study has been limited to the teaching process to measure the education effectiveness from the teachers' sight.

This study added a new contribution by investigating deeply the proper planning process needed for each phase of teaching, as a radical element of education, determining the level of proper planning at each phase, and thus opening a new gate for the future research to provide new methods for overcoming the educational obstacles facing other stages of teaching process.

\section{Recommendations}

Based on the study results, a set of recommendation aiming to support secondary school administration in Jordan can be provided, which are:

a. Establishment of a particular department, in each school, assigned to teaching planning. This department may be better organized to support teachers to do proper planning for effective teaching at all schools stages.

b. Directorates of Education in Jordan must build well cooperation and interactive communications with some universities to develop their teachers' performance in all teaching requirements.

c. Manifesting the role of teaching planning in raising the educational level and administrative performance of the staff in the school.

d. Supporting the teacher's guide with planning procedures that can assist the teacher how to manage their teaching planning effectively.

e. The ministry of education in Jordan (MOE) must try to benefit from the knowledge of some countries having high levels of planning and teaching in the schools' stages. This duty can be achieved through fetching the planning approaches adopted in those countries as well as inviting some experienced teachers in those countries to provide their methods for MOE How to implement these planning approaches properly.

\section{References}

Afsahi, S. E. (2016). The role of evaluation in curriculum design. Retrieved from https://www.researchgate.net/publication/309556210

Ahmad, M. (2011). Strategic Educational Planning: "Idea \& Application" (1st ed.). Amman: Dar Al Maseerah. 
Al Absi, M. (2004). Building Educational Guide of Strategic Planning in Jordanian High Schools. unpublished PHD Study, University of Jordan.

Al-Mohsen, M., \& Kilani, A. (2009). A proposed project to develop the basic education planning system in Jordan. Jordanian Journal of Educational Sciences, 6(1), 1-26.

Al-Qarni, A. K. (2012). Strategic Planning in General Education Schools in Taif Governorate (Proposed Scenario). Master Thesis, Umm Al-Qura University [in Arabic].

Alsharari, N. M. (2017).The development of accounting education and practice in an environment of socio-economic transformation in the Middle East: The case of Jordan. International Journal of Educational Management, 31(6), 736-751. https://doi.org/10.1108/IJEM-04-2016-0082

Al-Zboon, M. S., \& Hasan, M. S. (2014). Strategic School Planning In Jordan. Education, 132(4). Retrieved from https://www.researchgate.net/publication/308970765_Strategic_School_Planning_In_Jordan

Collins, M. (2016). The development of town planning education at University College London 1914-1969: the contributions of professors S. D. Adshead. Planning Perspectives, 31(2), 283-298. http://dx.doi.org/10.1080/02665433.2015.1094401

Drouze, A. (2011). The degree to which teachers in the Qalqilya Governorate schools respect the levels of knowledge of the goals of Bloom in their planning for teaching. Journal of Human Sciences, 25(1), 2-2559.

Fua, S. J. (2001). Values and leadership practices of secondary school principals in the Kingdom of Tonga. Unpublished Master's thesis, University of Toronto, Toronto. Retrieved from https://tspace.library.utoronto.ca/bitstream/1807/15980/1/MQ58713.pdf

Haddad, W. (1995). Fundamentals of educational planning. 7 place de Fontenoy, 75700, Paris: the United Nations Educational, Scientific and Cultural Organization.

Kellen, D. (1996). Curriculum Reform in Secondary Education: Planning, development, and implementation. European Journal of Education, 31(1), 43-55. Retrieved from https://www.jstor.org/stable/1503556?seq=1\#page_scan_tab_contents

Khan, H., \& Shah, M. (2002). Factors associated with learning achievement of grade-V students in public schools. Academy of Educational Planning and Management, Ministry of Education, Islamabad.

Khasawneh, S. (2011). Human capital planning in higher education institutions: A strategic human resource development initiative in Jordan. International Journal of Educational Management, 25(6), 534-544. https://doi.org/10.1108/09513541111159040

King, M. B. (2004). School and district-level leadership for teacher workforce development: enhancing teacher learning and capacity. In Smylie, M. and Miretzky, D. (Eds.), Developing the teacher workforce. Yearbook of the National Society for the Study of Education (pp. 303-23). Chicago, IL: University of Chicago Press.

Kombra, U. (2006). Provincial level education planning: an analysis of the process of planning and implementation of education reforms in Papua New Guinea. Unpublished MEd Hons thesis, University of New England, Armidale, NSW.

Lofstorm, E. (2007). From strategic planning to meaningful learning: diverse perspectives on the development of web-based teaching and learning in higher education. British Journal of Educational Technology, 38(2). https://doi.org/10.1111/j.1467-8535.2006.00625.x

Puamau, P. (2006). Educational Planning in the Pacific: principles and guidelines. Directions: Journal of $\begin{array}{llllll}\text { Educational } & \text { Studies, } & 28 & (1 \& 2), & \text { Retrieved } & \text { From }\end{array}$ http://www.paddle.usp.ac.fj/collect/paddle/index/assoc/pride043.dir/doc.pdf

Saeed, M., Gondal, M., \& Bushra, B. (2005). Assessing achievement of primary grader students and factors affecting achievement in Pakistan. International Journal of Educational Management, 19(6), 486-99. https://doi.org/10.1108/09513540510617436

Salfi, N. \& Saeed, M. (2007). Relationship among school size, school culture and students' achievement at secondary level in Pakistan. International Journal of Educational Management, 2(21), 606-620. https://doi.org/10.1108/09513540710822201

Stave, S., Tiltnes, A., Khalil, Z., \& Husseini, J. (2017). Improving learning environments in Jordanian public schools. 
https://ardd-jo.org/sites/default/files/resource-files/improving_learning_environments_in_jordanian_public_ schools.compressed_12_0.pdf

Thompson, S. (2002). Sampling, wiley series in probability and statistics. New Jersey: John Wiley and Sons.

\section{Copyrights}

Copyright for this article is retained by the author(s), with first publication rights granted to the journal.

This is an open-access article distributed under the terms and conditions of the Creative Commons Attribution license (http://creativecommons.org/licenses/by/4.0/). 